\title{
NEUROPROTECTIVE EFFECTS OF THE PINEAL HORMONE MELATONIN IN ANIMALS WITH EXPERIMENTAL MODELS OF NEURODEGENERATIVE PATHOLOGY
}

\section{Labunets I. F.}

\section{INTRODUCTION}

Multiple sclerosis is one of the most common demyelinating and neurodegenerative diseases of the central nervous system $(\mathrm{CNS})^{1}$. It is characterized by autonomic dysfunction and deficits in motor activity, memory, emotion, and intelligence. Although multiple sclerosis usually develops in young men and women, in recent years it has increasingly occurred in subjects over the age of 45 years.

The Parkinson's disease (PD) is a chronic progressive neurodegenerative disorder, in which massive loss of dopaminergic neurons in the substantia nigra of the midbrain leads to the dopamine insufficiency in the neostriatum and to the development of a classical complex of motor disorders: hypokinesia, rigidity, and tremor ${ }^{2}$. According to clinical observations, the non-motor symptoms, such as autonomic, sensory and cognitive abnormalities, depression, sleep disturbance, etc are also typical of PD together with motor disorders.

Oxidative stress and neuroinflammation are pathogenic factors of neuronal damage in multiple sclerosis and $\mathrm{PD}^{3}$. Microglial cells and macrophages in the brain produce free radicals and proinflammatory cytokine (TNF- $\alpha$, IFN- $\gamma$ and IL-1 $\beta$. During neuroinflammation the T-lymphocytes infiltrate the brain and become the source of prionflammatory cytokines ${ }^{4}$. Differentiation and activity of the T cells are known

${ }^{1}$ Mishchenko T.S., Shulga O.D., Bobryk N.V., Shulga L.A. Multiple Sclerosis: Global Perspectives. Ukr Med Chasopis-Ukr Med J. 2014. 101(3). P. 84-87 [Ukrainian].

${ }^{2}$ Karaban I.N., Karaban N.V., Karasevych N.V. The ways of neuroprotection in Parkinson's disease. INJ. 2011. № 6. P. 95-99 [Russian].

3 Abdurasulova I.N., Klimenko V.M. The role of immune and glial cells in neurodegeneration processes. Med. Akad. Zh. 2011. 11(1). P. 12-29 [Russian].

Guo J.-D., Zhao X., Li Y. et al. Damage to dopaminergic neurons by oxidative stress in Parkinson's disease (Review). Int J. of molecular medicine. 2018. 41. P. 1817-1825. DOI :10.3892/ijmm.2018.3406.

${ }^{4}$ Gonzalez H., Pacheco R. T-cell-mediated regulation of neuroinflammation involved in neurodegenerative diseases. J. Neuroinflammation. 2014. 11(201). $11 \mathrm{p}$. DOI 10.1186/s12974-014-0201-8. 
to be controlled by thymic hormone thymulin/serum thymic factor ${ }^{5}$. Thymulin influences macrophage activity and exhibits an anti-inflammatory effect by inhibiting proinflammatory cytokine synthesis ${ }^{6}$.

The pineal gland hormone melatonin affects immune and endocrine system functioning, controls the biological rhythms of various body functions and exibits antioxidant, antiapoptotic, anti-inflammatory and neurotrophic effects ${ }^{7}$. In contrast, the administration of melatonin to the animals of different age with nervous system pathology exhibits neuroprotective effects ${ }^{8}$. Melatonin synthesis is modified in multiple sclerosis and $\mathrm{PD}^{9}$.

The goal of the present study was to investigate changes of the immune system, neuroinflammation and oxidative stress factors, structural and functional CNS disorders in animals with models of neurodegenerative pathology. We also tried to estimate the efficiency of their improving after melatonin administration.

\section{Materials and methods}

Animals. Experiments were performed on 3-5- month (young, $n=32$ ) and 15-17-month old (aging, $n=32$ ) female $129 / \mathrm{Sv}\left(\mathrm{H}-2^{\mathrm{b}}\right.$ genotype) mice and on 3-4-month old (adult, $n=48$ ) male Wistar rats received from vivarium of the Institute of Genetic and Regenerative Medicine NAMS Ukraine. The animals were kept in standard vivarium conditions with a fixed

5 Csaba G. The immunoendocrine thymus as a pacemaker of lifespan. Acta Microbiol.Immunol. Hung. 2016. 63(2). P.139-158. DOI :10.1556/030.63.2016.2.1.

6 Labunets I.F., Rodnichenko A.E., Vasiliev R.G. Capacity of bone marrow granylocyte and macrophage precursors in mice of different strains for in vitro colony formation under changed thymuline level in the organism and cell cultures. Genes \& Cells. 2017. 12(2). P. 97-103.

DOI 10.23868/201707021.

Haddad J.J., Hanbali L.H. The anti-inflammatory and immunomodulatory activity of thymulin peptide is NF-kB dependent and involves the downregulation of I kB- $\alpha$. Am. J. Med. Biol. Res. 2013.1(2). P. 41-49.DOI 10.12691/ajmbr-1-2-2.

${ }^{7}$ Sarlak G., Jenwitheesuk A, Chetsawang B., Govitrapong P. Effects of melatonin on nervous system aging: neurogenesis and neurodegeneration. J. Pharmacol.Sci. 2013. 123. P. 9-24. PMID:23985544.

Wurtman R. Multiple sclerosis, melatonin and neurobehavioral diseases. Front. Endocrinol. 2017. 8. Article 280 |DOI :10.3389/fendo.2017.00280.

${ }^{8}$ Hardeland R. Melatonin in aging and diseases-multiple consequences of reduced secretion. Options and limits of treatment. Aging Dis., 3(2). P. 194-225. www.aginganddisease.org.

${ }^{9}$ Labunets I.F. Age-related changes in the melatonin and thymulin biorhythms as risk factors for human neurodegenerative diseases. Gerontol\&Geriatric Stud. 1(2). GGS.000506.2017. 5 p. 
light regimen 12:12. Biological tissues for studies were taken in the morning by ether anesthesia. All experiments were carried out according to the European Convention for the Protection of Vertebrate Animals used for Experimental and other Scientific Purposes (Strasburg, 1986).

Cuprizone-induced model of demyelination and neurodegeneration. The mice were given neurotoxin cuprizone [bis(cyclohexylidenehydrazide)] (Sigma, USA) in the amount of $0.2 \%$ by weight, mixed with food, daily for three weeks ${ }^{10}$.

Model of hemiparkinsonism. To create the state of experimental hemiparkinsonism (HP), the rats were stereotaxically injected into left forebrain lateral ascending bundle with $8.0 \mu \mathrm{g}$ neurotoxin 6-hydroxydopamine (6-HODA, Sigma, USA) in $4.0 \mu \mathrm{l}$ of the solvent ${ }^{11}$. The rats with sham introductions (ShI) obtained stereotaxic injections into the analogous cerebral locus of $4.0 \mu \mathrm{l}$ of the solvent with no neurotoxin. All manipulations were performed under barbiturate anesthesia $(50 \mathrm{mg} / \mathrm{kg}$ Nembutal, Sigma, USA).

One week after stereotaxic microinjections of 6-HODA, rats of the general HP group were subjected to test intraperitoneal (i.p.) injections of an agonist of dopamine receptors, apomorphine $(0.5 \mathrm{mg} / \mathrm{kg}$, Sigma, USA). Then, the intensity of circulatory movements (number of body rotations per $1 \mathrm{~min}$ ) to the side contralateral to the hemisphere where the neurotoxin was injected was estimated. Two animal groups, with low and high intensities of circulatory movements induced by apomorphine $\left(\mathrm{HP}<1\right.$ and $\mathrm{HP}_{\geq 6}$, respectively) were formed.

Injections of melatonin. Cuprizone-treated mice of both age groups received melatonin i.p. injections (Sigma, USA) in the dose of $1 \mathrm{mg} / \mathrm{kg}$ every day at 6 p.m. starting from the eighth day of the cuprizone diet and until the end of the experiment. Two groups of young and aging mice received cuprizone and solvent injections. In addition, two intact groups of young and aging mice were used.

${ }^{10}$ Praet J., Guglielmetti C., Berneman Z. et al. Cellular and molecular neuropathology of the cuprizone mouse model: Clinical relevance for multiple sclerosis. Neubiorev. 2014. 47. P. 485-505. doi.org/10.1016/j.neubiorev.2014.10.004.

Labunets I.F., Rodnichenko A.E. Melatonin effects in young and aged mice with toxic cuprizone-induced model of demyelination. Adv. Gerontol. 2019. 32(3). P. 338-346. [Russian]. PMID:31512419.

${ }^{11}$ Labunets I.F., Chaikovsky Yu.B., Savosko S.I. et al. Effects of melatonin on the behavioral indices and structural characteristics of cerebral and spinal neurons of rats with experimental hemiparkinsonism. Neurophysiology. 2018. 50(1). P. 11-22. DOI 10.1007/s11062-018-9712-8. 
Beginning from the $5^{\text {th }}$ day after apomorphine test, parts of the rats of $\mathrm{HP}_{<1}$ and $\mathrm{HP}_{\geq 6}$ groups were i.p. injected either with melatonin $(10 \mathrm{mg} / \mathrm{kg}$, daily, for 18 days, injections at 6 p.m.) or with pure solvent of this hormone. Intact rats were also used in our experiments.

Neural cell phenotypes were determined based on the CD3, Mac1 and nestin markers (T-lymphocytes, macrophages and neural stem cells markers, respectively) with monoclonal antibodies conjugated to a fluorochrome at a concentration of $0.5 \mu \mathrm{g} / \mathrm{ml}$ (Becton Dickinson, USA). The measurements were performed on a BD FACSAria flow cytofluorimetr (Becton Dickinson, USA).

Functional activity of brain macrophages. The percentage of brain macrophages capable to phagocytosis of latex beads (phagocytic index) and the amount of latex beads, which phagocyte used by one macrophage (phagocytic activity) were counted under light microscope ${ }^{12}$.

The malondialdehyde (MDA) level was determined in the brain and blood of experimental animals according to Uchiyama ${ }^{13}$.

The thymus function was assessed by thymulin titer $\left(\log _{2}\right)$ in the blood ${ }^{14}$.

For morphological studies of the CNS structures (cerebral cortex, substantia nigra of the midbrain) the histological sections were stained with toluidine blue (by Nissl). The percentage of structurally unchanged neurons was determined by the morphometric analysis (Carl Zeiss JENA Docuval microscope, Germany).

The state of neurogenesis was assessed via comparison of the data obtained from the nestin ${ }^{+}$cells and structurally unchanged neurons in the brain.

Behavioral phenomena in animals ${ }^{15}$. Behavioral reactions in mice were studied using "open field" test. It assesses the horizontal activity (the number of squares crossed), the exploratory activity (hole peeking and the number of

${ }^{12}$ Labunets I.F., Melnyk N.O., Rodnichenko A.E. et al. Cuprizone-induced disorders of central nervous system neurons, behavioral reactions, brain activity of macrophages and antioxidant enzymes in the mice of different ages: role of leukemia inhibitory factor in their improvement. J. Aging Geriatr. Med. 2017. 1(2). 8 p. Doi: 10.4172/AGM.1000104.

${ }^{13}$ Uchiyama M., Mihara M. Determination of malonaldehyde precursor in tissues by thiobarbituric acid test. Anal. Biochem. 1978. 86(1). P. 271-278. DOI 10.1016/00032697(78)90342-1

14 Labunets I.F., Rodnichenko A.E., Vasiliev R.G. Capacity of bone marrow granylocyte and macrophage precursors in mice of different strains for in vitro colony formation under changed thymuline level in the organism and cell cultures. Genes \& Cells. 2017. 12(2). P. 97-103.

DOI 10.23868/201707021.

${ }^{15}$ Amikishieva AV. Behavioral phenothyping: up-to date methods and equipment. Vestnik VOGiS. 2009. 13(3). P. 529-542. 
rearing) and the emotional state (the number of fecal boluses). The duration of the open field test in mice was 3 min.

Behavioral indices in the rats were estimated in the open field test and the elevated plus maze test. In open field test the observation period lasted 3 min. In the elevated plus maze test, we estimated the level of anxiety in rats. The animals were placed on the central platform of the maze, and times (sec) spent in the open arms, closed arms and on the central open platforms of the maze were measured within the 5-min-long observation period.

Statistical analysis of the results was carried out using the Student's $\mathrm{t}$-criterion. Differences between the means of comparable groups $(\mathrm{M} \pm \mathrm{SEM})$ were significant at $\mathrm{p}<0.05$.

\section{Results and Discussion}

2.1. Melatonin effects in young and aging mice with the toxic cuprizone-induced demyelination and neurodegeneration

As summarized in Table 1, the proportion of $\mathrm{CD}^{+}$and $\mathrm{Mac1}^{+}$cells in the brain of 3-5 and 15-17 month old cuprizone-treated mice was significantly higher than in intact animals. Melatonin injections led to a decrease in the proportion of $\mathrm{CD}^{+}$and $\mathrm{Mac}^{+}$cells in both age groups, and their levels reached the values observed in the intact groups.

The MDA content in the brain of 3-5 and 15-17-month old mice fed a cuprizone-enriched diet was higher than in the intact animals. After melatonin administration the MDA content decreased to the values of the intact mice.

Our study demonstrated that the number of nestin ${ }^{+}$cells in the brain of 3-5 and 15-17-month old mice increased significantly after the use of cuprizone and decreased in response to melatonin injections. Notably, the number of nestin ${ }^{+}$ cells in young mice reached the values observed in the intact group.

Melatonin administration resulted in an increase the thymulin blood level in cuprizone-treated mice of both age groups as compared to the groups treated with neurotoxin alone. In addition, the values of the indices differed significantly $(p<0.05)$ between young and aging mice receiving melatonin.

The proportion of unchanged neurons in the cerebral cortex of young intact mice and animals after cuprizone administration, including in a combination with melatonin injections, was $92 \pm 8,9 \pm 2$ and $32 \pm 5 \%$, respectively. In the similar groups of aging mice, the proportion of unchanged neurons was $85 \pm 5,10 \pm 2$ and $53 \pm 4 \%$, respectively. The values of the indices decreased in both age groups of cuprizone-treated mice $(p<0.05)$. After melatonin administration, there was an increase in the proportion of unchanged neurons in young and aging mice $(p<0.05)$. However, this number was still lower than in the intact mice $(p<0.05)$. 
Table 1

Proportion of $\mathrm{CD3}^{+}, \mathrm{Mac1}^{+}$, nestin ${ }^{+}$cells and MDA content in the brain and thymuline blood level in mice of the experimental groups, $M \pm m$

\begin{tabular}{|c|c|c|c|}
\hline \multirow[b]{2}{*}{ Indices } & \multicolumn{3}{|c|}{ Groups of mice } \\
\hline & Intact & $\begin{array}{c}\begin{array}{c}\text { Cuprizone+ } \\
\text { solvent }\end{array} \\
\end{array}$ & $\begin{array}{c}\text { Cuprizone+ } \\
\text { Melatonin }\end{array}$ \\
\hline \multicolumn{4}{|c|}{ 3-5-month old mice } \\
\hline $\mathrm{CD}^{+}, \%$ & $0.9 \pm 0,1$ & $1.7 \pm 0,2^{*}$ & $0.9 \pm 0.1^{\#}$ \\
\hline $\mathrm{Mac1}^{+}, \%$ & $1.4 \pm 0,1$ & $1.9 \pm 0.2 *$ & $1.6 \pm 0.1$ \\
\hline $\mathrm{MDA}, \mathrm{nmol} / \mathrm{mg}$ & $3.3 \pm 0,2$ & $4.2 \pm 0.3^{*}$ & $3.2 \pm 0.2$ \\
\hline $\mathrm{Nestin}^{+}, \%$ & $1.4 \pm 0.1$ & $2.2 \pm 0.2^{*}$ & $1.5 \pm 0.1$ \\
\hline Thymulin, $\log _{2}$ & $5.5 \pm 0,2$ & $6.1 \pm 0.5$ & $8.3 \pm 0.6^{* \#}$ \\
\hline \multicolumn{4}{|c|}{ 15-17-month old mice } \\
\hline $\mathrm{CD}^{+}, \%$ & $1.2 \pm 0.1^{\&}$ & $1.8 \pm 0.2^{*}$ & $1.2 \pm 0.1^{\# \&}$ \\
\hline $\mathrm{Mac1}^{+}, \%$ & $0.4 \pm 0.1^{\&}$ & $0.8 \pm 0.1 * \&$ & $0.6 \pm 0.1^{\&}$ \\
\hline $\mathrm{MDA}, \mathrm{nmol} / \mathrm{mg}$ & $3.7 \pm 0.2$ & $4.8 \pm 0.4^{*}$ & $2.9 \pm 0.5^{\#}$ \\
\hline $\mathrm{Nestin}^{+}, \%$ & $1.7 \pm 0.2$ & $2.9 \pm 0.2 * \&$ & $1.2 \pm 0.1^{* \# \&}$ \\
\hline Thymulin, $\log _{2}$ & $4.9 \pm 0.2^{\&}$ & $5.6 \pm 0.6$ & $6.8 \pm 0.4^{* \&}$ \\
\hline
\end{tabular}

Footnotes: * $\mathrm{p}<0,05$ intact group; ${ }^{\#} \mathrm{p}<0,05$ cuprizone; ${ }^{\alpha} \mathrm{p}<0,05$ age of 3-5 months (Here and in Table 2)

As summarized in Table 2, the behavioural indices in the open field test in mice of both age groups treated with cuprizone were significantly lower than those in intact animals. In young and aging mice, the number of squares crossed increased after melatonin administration. Moreover, the values in aging mice reached those found in the intact animal. Peeking and rearing activity increased after melatonin injections only in young cuprizone-treated animals. The numbers of boluses increased in mice of both age groups after melatonin injections and does did not differ from those in the intact groups.

Table 2

Behavioral indices in mice of the experimental groups, $M \pm m$

\begin{tabular}{|c|c|c|c|}
\hline \multirow{2}{*}{ Indices } & \multicolumn{3}{|c|}{ Groups of mice } \\
\cline { 2 - 4 } & Intact & $\begin{array}{c}\text { Cuprizone+ } \\
\text { solvent }\end{array}$ & $\begin{array}{c}\text { Cuprizone+ } \\
\text { melatonin }\end{array}$ \\
\hline \multicolumn{4}{|c|}{$3-5$-month old mice } \\
\hline $\begin{array}{c}\text { Number of } \\
\text { squares } \\
\text { boluses }\end{array}$ & $51.2 \pm 3.6$ & $15.1 \pm 2.5 *$ & $36.2 \pm 2.4 *^{\#}$ \\
\hline
\end{tabular}


Table 2 (ending)

\begin{tabular}{|c|c|c|c|}
\hline \multirow{2}{*}{ Indices } & \multicolumn{3}{|c|}{ Groups of mice } \\
\cline { 2 - 4 } & Intact & $\begin{array}{c}\text { Cuprizone+ } \\
\text { solvent }\end{array}$ & $\begin{array}{c}\text { Cuprizone+ } \\
\text { melatonin }\end{array}$ \\
\hline $\begin{array}{c}\text { Number of } \\
\text { rearing }\end{array}$ & $0.3 \pm 0.02$ & $0.11 \pm 0.03 *$ & $0.25 \pm 0.02^{\#}$ \\
\hline $\begin{array}{c}\text { Number of } \\
\text { "holes" }\end{array}$ & $1.6 \pm 0.3$ & $0.6 \pm 0.1 *$ & $0.9 \pm 0.1 *^{\#}$ \\
\hline \multicolumn{4}{|c|}{$15-17-$ month old mice } \\
\hline $\begin{array}{c}\text { Number of } \\
\text { squares }\end{array}$ & $43.5 \pm 2.9^{\&}$ & $17.2 \pm 3.4 *$ & $40.4 \pm 4.1^{\#}$ \\
\hline $\begin{array}{c}\text { Number of } \\
\text { boluses }\end{array}$ & $2.2 \pm 0.3$ & $1.2 \pm 0.2 *$ & $1.8 \pm 0.3^{\#}$ \\
\hline $\begin{array}{c}\text { Number of } \\
\text { rearing }\end{array}$ & $0.45 \pm 0.08$ & $0.1 \pm 0.05 *$ & $0.25 \pm 0.03^{*}$ \\
\hline $\begin{array}{c}\text { Number of } \\
\text { "holes" }\end{array}$ & $1.8 \pm 0.3$ & $0.1 \pm 0.05 * \&$ & $0.2 \pm 0.04 * \&$ \\
\hline
\end{tabular}

Therefore, unidirectional changes in blood thymuline level, the number of $\mathrm{CD}^{+}$and $\mathrm{Mac}^{+}$cells, the MDA content in the brain were observed in both young and aging mice with cuprizone-induced demyelination and neurodegeneration. Irrespective to animal age, melatonin injections led to positive changes in the examined indices.

Besides, the use of cuprizone led to a decrease in the proportion of unchanged neurons in CNS and to the reduction of behavioural responses. At the same time, an improvement of behavioural performance was observed in young and aging mice receiving melatonin and accompanied by an increase in the proportion of unchanged neurons and the reduction of the percentage of nestin ${ }^{+}$cells in the brain. The effect melatonin on behavioural performance was more pronounced in young cuprizone-treated mice as compared to aging animals.

2.2. Melatonin effects in adult rats with model of experimental hemiparkinsonism

As shown in Table 3, the number of active macrophages in the brain was significantly higher in groups $\mathrm{HP}<_{1}$ and $\mathrm{HP}_{\geq 6}$ compared to sham-injected rats. After melatonin injections the phagocytic activity of brain macrophages significantly decreased only in group $\mathrm{HP}_{\geq 6}$ with melatonin treatment relative to group $\mathrm{HP}_{\geq 6}$ without melatonin.

The MDA content in the brain of rats group $\mathrm{HP}_{\geq 6}$ was higher than in sham-injected rats. After melatonin administration the content of MDA decreased to the value of control rats. 
Table 3

The indices of macrophage activity and content of MDA in brain of the experimental rats, $M \pm m$

\begin{tabular}{|c|c|c|c|}
\hline \multirow{2}{*}{$\begin{array}{c}\text { Exprimental } \\
\text { groups of rats }\end{array}$} & \multicolumn{2}{|c|}{$\begin{array}{c}\text { Indices of macrophage activity } \\
\text { in the midbrain }\end{array}$} & \multirow{2}{*}{$\begin{array}{c}\text { MDA, } \\
\text { nmol/mg }\end{array}$} \\
\cline { 2 - 3 } & $\begin{array}{c}\text { Fagocytic } \\
\text { index, \% }\end{array}$ & $\begin{array}{c}\text { Fagocytic } \\
\text { activity }\end{array}$ & \\
\hline Sham-injected & $85.1 \pm 1.0$ & $2.5 \pm 0.3$ & $3.7 \pm 0.2$ \\
\hline $\mathrm{HP}_{<1}$ & $88.2 \pm 1.0^{*}$ & $4.2 \pm 0.4^{*}$ & - \\
\hline $\mathrm{HP}_{\geq 6}$ & $90.0 \pm 2.2^{*}$ & $5.5 \pm 0,3^{*}$ & $4.8 \pm 0.3^{*}$ \\
\hline $\mathrm{HP}_{<1}+\mathrm{M}$ & $86.1 \pm 1.0$ & $4.0 \pm 0.2^{*}$ & - \\
\hline $\mathrm{HP}_{\geq 6}+\mathrm{M}$ & $92.2 \pm 2.3^{*}$ & $4.5 \pm 0.2^{*}$ & $3.6 \pm 0.2$ \\
\hline
\end{tabular}

Footnotes. HP-hemiparkinsonism, M-melatonin. $\mathrm{p}<0.05$ compared with: * shaminjected, \# group $\mathrm{HP}_{\geq 6}$

It has been revealed that the endocrine function of the thymus in shaminjected rats was suppressed compared to intact animals, which can be explained by the gland reaction to surgery (Fig.). In the rats demonstrating circulatory movements, the blood levels of thymulin were are significantly reduced relative to sham-injected animals. After a course of melatonin, the thymulin level increased $(p<0.05)$ in rats of both research groups to the values in intact animals (Fig. 1).

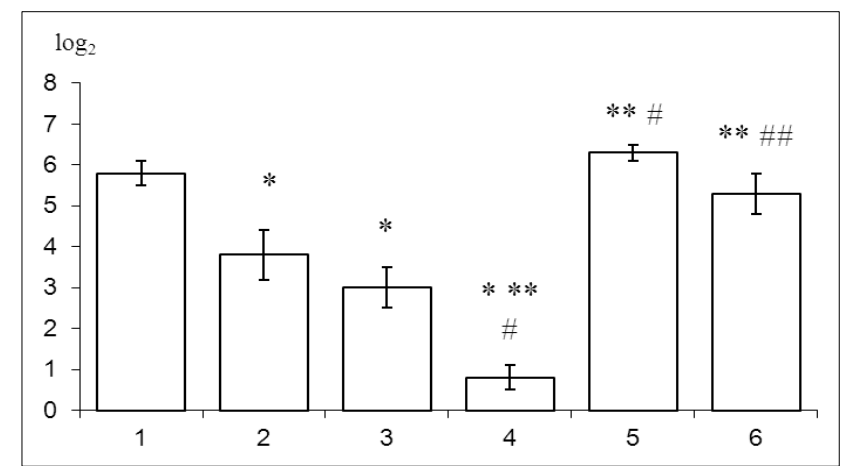

Fig. 1. The thymulin level in the blood samples of rats with experimental hemiparkinsonism (HP) and its changes after melatonin treatment:

1-intact, 2-sham-injected animals, 3-group $\mathrm{HP}<1,4$-group $\mathrm{HP}_{\geq 6}$, 5 -group $H P_{<1}$ and with the administration of melatonin, 6-group $H P_{\geq 6}$ and melatonin treatment; $p<0.05$ compared $*$ with intact rats, ** sham-injected, \# group $\mathrm{HP}<1$, \#\# group $\mathrm{HP}_{\geq 6}$ 
The number of structurally unchanged neurons in the substantia nigra was greater in group $\mathrm{HP}_{<1}$ than in group $\mathrm{HP}_{\geq 6}$ (respectively $25 \pm 2$ and $15 \pm 2 \%, p<0.05)$. The indices were lower than in intact rats $(98 \pm 3 \%$, $p<0.05)$. The number of unchanged nigral neurons in rats with experimental $\mathrm{HP}$ injected with melatonin (35 \pm 3 and $32 \pm 2 \%$ in groups $\mathrm{HP}<1+\mathrm{M}$ and $\mathrm{HP}_{\geq 6}+\mathrm{M}$, respectively) were considerably more $(p<0.05)$ than those in experimental animals without melatonin injections.

In rats with weak experimental HP manifestations (group $\mathrm{HP}<1$ ), the intensity of locomotor activity (mean number of crossed squares of the arena), was, on average, $40 \%$ of that in the intact and sham-injected groups (See Table 4). In rats with intense manifestations of such pathology (group $\mathrm{HP}_{\geq 6}$ ), suppression of locomotor activity was dramatic (20 times, $p<0.001$ ). The number of rearings with support in group $\mathrm{HP}_{<1}$ was somewhat smaller with respect to the two control groups (intact and sham-injected), but the difference was significant. In group $\mathrm{HP}_{\geq 6}$, this index demonstrated more than a fourfold decrease $(p<0.01)$. Suppression of such manifistations of orientation activity as rearing without support, in groups $\mathrm{HP}<1$ and $\mathrm{HP}_{\geq 6}$ was more intense; it was, respectively, about fourfold $(p<0.01)$ and by an order of magnitude $(p<0.01)$. The number of acts of defecation in the two above-mentioned groups within the observation periods was smaller than in the intact and sham-injected groups; however, the rather low frequency of such acts and the high variability of the index did not allow us to formulate concrete conclusions with respect to this behavioral component.

Course injections of melatonin did not change significantly the intensity of locomotion in group $\mathrm{HP}<1+\mathrm{M}$, as compared with the respective index in group $\mathrm{HP}<1$. At the same time, the index in the group with intense manifestations of experimental $\mathrm{HP}\left(\mathrm{HP}_{\geq 6}+\mathrm{M}\right)$ exceeded nearly three times the analogous index in rats receiving no injection of melatonin (group $\mathrm{HP}_{\geq 6}$ ). On the whole, injections of this hormone did not result in considerable systematic shifts in the number of rearings of both types and act of defecations, compared with analogous indices in groups $\mathrm{HP}_{<1}$ and $\mathrm{HP}_{\geq 6}$.

After microinjections of 6-HODA the time spent in open arms of the maze (elevated plus maze test) in rats of both experimental groups ( $\mathrm{HP}<1$ and $\mathrm{HP}_{\geq 6}$ ) was smaller than that in control (intact and sham-injected) animals (the difference was fourfold or even greater, $p<0.01$ ) (See Table 5). In rats with experimental HP, the time spent in the center was also significantly smaller compared with control, especially in group $\mathrm{HP}_{\geq 6}(p<0.01)$. 
Behavioral indices in rats of the experimental groups in the open field test, $M \pm m$

\begin{tabular}{|c|c|c|c|c|}
\hline \multirow{2}{*}{$\begin{array}{c}\text { Experimental } \\
\text { groups }\end{array}$} & $\begin{array}{c}\text { Number of } \\
\text { crossed } \\
\text { squares }\end{array}$ & $\begin{array}{c}\text { Number of } \\
\text { rearing with } \\
\text { support }\end{array}$ & $\begin{array}{c}\text { Number } \\
\text { rearing without } \\
\text { support }\end{array}$ & $\begin{array}{c}\text { Number } \\
\text { of boluses }\end{array}$ \\
\hline Intact (I) & $78 \pm 16$ & $7.5 \pm 0.8$ & $3.4 \pm 1.0$ & $1.9 \pm 0.6$ \\
\hline Sham-injected (ShI) & $72 \pm 12$ & $8.3 \pm 1.1$ & $4.3 \pm 1.0$ & $2.7 \pm 0.6$ \\
\hline $\begin{array}{c}\text { Mean value for } \\
\text { groups I and ShI }\end{array}$ & $75(100 \%)$ & $7.9(100 \%)$ & $3.85(100 \%)$ & $2.3(100 \%)$ \\
\hline $\mathrm{HP}_{<1}$ & $\begin{array}{c}30 \pm 11 * * * \\
(40 \pm 15 \%)\end{array}$ & $\begin{array}{c}6.3 \pm 2.8 \\
(80 \pm 35 \%)\end{array}$ & $\begin{array}{c}1.1 \pm 0.3 * * * \\
(28 \pm 8 \%)\end{array}$ & $\begin{array}{c}1.4 \pm 0.4 \\
(61 \pm 17 \%)\end{array}$ \\
\hline $\mathrm{HP} \geq 6$ & $\begin{array}{c}4.0 \pm 0.8 * * * \wedge \\
(5 \pm 1 \%)\end{array}$ & $\begin{array}{c}1.4 \pm 0.6 * * * \\
(18 \pm 7 \%)\end{array}$ & $\begin{array}{c}0.4 \pm 0.1 * * * \wedge \\
(10 \pm 2 \%)\end{array}$ & $\begin{array}{c}2.0 \pm 0.6 \\
(87 \pm 26 \%)\end{array}$ \\
\hline $\mathrm{HP}_{<1}+\mathrm{M}$ & $\begin{array}{c}29 \pm 9 * * * \\
(39 \pm 12 \%)\end{array}$ & $\begin{array}{c}5.9 \pm 1.1 \\
(75 \pm 14 \%)\end{array}$ & $\begin{array}{c}1.0 \pm 0.2 * * * \\
(26 \pm 5 \%)\end{array}$ & $\begin{array}{c}1.8 \pm 0.5 \\
(78 \pm 22 \%)\end{array}$ \\
\hline $\mathrm{HP}_{\geq 6}+\mathrm{M}$ & $\begin{array}{c}10.6 \pm 1.2 * * * \alpha \\
(14 \pm 2 \%)\end{array}$ & $\begin{array}{c}1.4 \pm 0.4 * * * \wedge \\
(18 \pm 5 \%)\end{array}$ & $\begin{array}{c}0.6 \pm 0.2 * * * \\
(16 \pm 5 \%)\end{array}$ & $\begin{array}{c}1.7 \pm 0.9 \\
(74 \pm 40 \%)\end{array}$ \\
\hline
\end{tabular}

Footnotes: HP - hemiparkinsonism; M-melatonin; $\mathrm{p}<0.05$ compared with: *intact, ***sham-injected, ${ }^{\&}$ group $\mathrm{HP}_{\geq 6},{ }^{\wedge}$ group $\mathrm{HP}<1$ (Here and in Table 5)

Table 5

Behavioral indices in rats in the elevated plus maze test, $M \pm \mathbf{m}$

\begin{tabular}{|c|c|c|c|c|}
\hline \multirow{2}{*}{$\begin{array}{c}\text { Experimental } \\
\text { groups }\end{array}$} & $\begin{array}{c}\text { Time spent in } \\
\text { open arms, sec }\end{array}$ & $\begin{array}{c}\text { Time spent in } \\
\text { closed arms, } \\
\text { sec }\end{array}$ & $\begin{array}{c}\text { Time spent in } \\
\text { the center, sec }\end{array}$ & $\begin{array}{c}\text { Number of looking } \\
\text { downwards }\end{array}$ \\
\hline Intact (I) & $159 \pm 38$ & $155 \pm 32$ & $43 \pm 3$ & $14 \pm 1$ \\
\hline $\begin{array}{c}\text { Sham-injected } \\
(\text { ShI })\end{array}$ & $121 \pm 19$ & $174 \pm 19$ & $45 \pm 4$ & $16 \pm 3$ \\
\hline $\begin{array}{c}\text { Mean value for } \\
\text { groups I and ShI }\end{array}$ & $140(100 \%)$ & $164.5(100 \%)$ & $44(100 \%)$ & $15(100 \%)$ \\
\hline $\mathrm{HP}_{<1}$ & $\begin{array}{c}22 \pm 12 * * * \\
(16 \pm 8 \%)\end{array}$ & $\begin{array}{c}247 \pm 47 \\
(150 \pm 28 \%)\end{array}$ & $\begin{array}{c}30 \pm 11 \\
(68 \pm 25 \%)\end{array}$ & $\begin{array}{c}4.3 \pm 1.0 * \\
* *(29 \pm 7 \%)\end{array}$ \\
\hline $\mathrm{HP}_{\geq 6}$ & $\begin{array}{c}25 \pm 8 * * * \\
(18 \pm 6 \%)\end{array}$ & $\begin{array}{c}232 \pm 15 * * * \\
(141 \pm 9 \%)\end{array}$ & $\begin{array}{c}12 \pm 3 * * * \\
(27 \pm 7 \%)\end{array}$ & $\begin{array}{c}3 \pm \pm 1 * * * \\
(20 \pm 7 \%)\end{array}$ \\
\hline $\mathrm{HP}_{<1}+\mathrm{M}$ & $\begin{array}{c}18 \pm 4 * * * \\
(13 \pm 3 \%)\end{array}$ & $\begin{array}{c}272 \pm 12 * * * \\
(165 \pm 7 \%)\end{array}$ & $\begin{array}{c}22 \pm 4 * * * \\
(50 \pm 9 \%)\end{array}$ & $\begin{array}{c}3.6 \pm 0.9 * \\
* *(24 \pm 6 \%)\end{array}$ \\
\hline $\mathrm{HP}_{\geq 6}+\mathrm{M}$ & $\begin{array}{c}152 \pm 36 * \wedge \\
(108 \pm 26 \%)\end{array}$ & $\begin{array}{c}132 \pm 32 * \wedge \\
(80 \pm 19 \%)\end{array}$ & $\begin{array}{c}21 \pm 5 * * * \\
(48 \pm 11 \%)\end{array}$ & $\begin{array}{c}2.5 \pm 0.5 * \\
* *(17 \pm 3 \%)\end{array}$ \\
\hline
\end{tabular}


Course melatonin injections did not result in significant changes in the time spent in open arms in the rats of group $\mathrm{HP}<1+\mathrm{M}$, as compared with group $\mathrm{HP}_{<1}$. In group $\mathrm{HP}_{\geq 6}+\mathrm{M}$ this indice was, however, significantly greater $(p<0.01)$ than in group $\mathrm{HP}_{\geq 6}$ that obtained no melatonin. The time spent in the center of the maze in rats of group $\mathrm{HP}_{\geq 6}+\mathrm{M}$ was significantly greater $(p<0.05)$ than the analogous index in animals that were not injected with melatonin $\left(\mathrm{HP}_{\geq 6}\right)$.

Therefore, the decrease of blood thymulin level and the increase of the contents of MDA and active macrophages in the brain of adult rats with experimental hemiparkinsonism model were observed. Besides, in experimental rats the proportion of unchanged neurons in substantia nigra decreased and behavioral responses changed. Melatonin injections led to positive changes in the examined indices.

The protective effect of melatonin on neurons in animals with experimental models of CNS pathology is associated with its antioxidant, anti-inflammatory, and antiapoptotic action ${ }^{16}$. We also demonstrated the antioxidant action of melatonin both in cuprizone-treated mice of different ages and adult rats with HP.

The anti-inflammatory effect of melatonin in above-mentioned experimental animals may be associated with its suppressing action on the number of brain microglial cells/macrophages and T-lymphocytes. Of the $\mathrm{T}$ cells, melatonin suppresses the $\mathrm{T}$-helper formation into $\mathrm{T}$ helper 17 line cells which produce pro-inflammatory cytokine IL-17. This cytokine enhances the demyelinating effect of cuprizone ${ }^{17}$.

In addition, thymulin can effect production of $\mathrm{T}$ helpers, decrease the synthesis of proinflammatory cytokines (IL-1 $\beta$, IL- 6 , TNF- $\alpha$, and others), and enhance the synthesis anti-inflammatory cytokines (IL-10) in the brain of animals with the neuroinflammation ${ }^{18}$. As shown in our previous study, the considerably decreased level of thymulin in the blood of rats with HP was restored to nearly control values after melatonin injections. In addition, there was a significant increase of the thymulin level in the blood of cuprizone-treated mice. Since in vitro melatonin affects thymulin production

${ }^{16}$ Sarlak G., Jenwitheesuk A, Chetsawang B., Govitrapong P. Effects of melatonin on nervous system aging: neurogenesis and neurodegeneration. J. Pharmacol.Sci. 2013. 123. P. 9-24. PMID: 23985544.

${ }^{17}$ Kang Z., Liu L., Spangler R. et al. IL-17-induced Act1-mediated signaling is critical for cuprizone-induced demyelination. J. Neurosci. 2012. 32(4) P. 8284-8292. DOI 10.1523/JNEUROSCI.0841-12.2012.

${ }^{18}$ Haddad J.J., Hanbali L.H. The anti-inflammatory and immunomodulatory activity of thymulin peptide is NF-kB dependent and involves the downregulation of I kB- $\alpha$. Am. J. Med. Biol. Res. 2013.1(2). P. 41-49. DOI 10.12691/ajmbr-1-2-2. 
in the thymus of young and aging mice ${ }^{19}$ and increase of blood thymulin level in the animals with experimental neurodegenerative pathology, it can be assumed that one of the possible mechanisms of the realization of the anti-inflammatory effect of melatonin in these animals is associated with alteration of the thymus endocrine function.

One more probable mechanism of realization of the neuroprotective effect of melatonin in cuprizone-treated mice and rats with PD is activation of neurogenesis in the CNS. Melatonin is known to affect proliferation and differentiation of neural stem cells in the key neurogenic niches (subventricular zone of the brain lateral ventricles, hippocampus, and olfactory bulb) ${ }^{20}$. It is possible that reduced proportion of nestin ${ }^{+}$cells observed in the brain of cuprizone-treated mice after melatonin administration results in increased differentiation of these cells into neurons. Indeed, the proportion of unchanged neurons in the brains of mice increases after melatonin injection and is accompanied by an improved functional state of the CNS as assessed by behavioural performance. A similar trend of changes in the proportion of nestin ${ }^{+}$cells and unchanged neurons in the brain and behavioural performance were observed in animals with experimental $\mathrm{HP}$ receiving melatonin ${ }^{21}$. Melatonin is known to stimulate the synthesis of a number of neurotrophic factors in the brain, including BDNF (brain-derived neurotrophic factor) and NGF (nerve growth factor).

The remyelinating effect of melatonin on the axons of the corpus callosum in young mice treated with cuprizone is mediated by antioxidant action and recovery of the activity of mitochondrial enzymes ${ }^{22}$. We found remyelinating effect of melatonin in vitro on the axons of neurons in a

${ }^{19}$ Labunets I.F., Butenko G.M., Khavinson V.Kh. Effects of bioactive factors of the pineal gland on thymus function and cell composition of the bone marrow and spleen in mice of different age. Bull Exp Biol Med. 2004. 137(5). P. 510-512. PMID:15455131

${ }^{20}$ Sarlak G., Jenwitheesuk A, Chetsawang B., Govitrapong P. Effects of melatonin on nervous system aging: neurogenesis and neurodegeneration. J. Pharmacol.Sci. 2013. 123. P. 9-24. PMID: 23985544.

${ }^{21}$ Labunets I.F., Chaikovsky Yu.B., Savosko S.I. et al. Effects of melatonin on the behavioral indices and structural characteristics of cerebral and spinal neurons of rats with experimental hemiparkinsonism. Neurophysiology. 2018. 50(1). P.11-22. DOI 10.1007/s11062-018-9712-8.

Labunets I.F., Talanov S.A., Vasilyev R.G. et al. Thymic hormones, antioxidant enzymes and neurogenesis in bulbus olfactorius of rats with hemiparkinsonism: effect of melatonin. Int. J. Phys. Pathophys. 2016. 7(4). P. 285-298. DOI 10.1615/IntJPhys Pathophys.v7.i4.10.

${ }^{22}$ Kashani I.R., RaJabi Z., Akbari M. et al. Protective effects of melatonin against mitochondrial injury in a mouse model of multiple sclerosis. Exp. Brain Res. 2014. 232(9). P. 2835-2846. DOI 10.1007/s00221-014-3946-5. 
cuprizone-demyelinated dissociated culture of cerebella cells in mice ${ }^{23}$. The effect was associated with an increased proportion of Olig2 cells in the demyelinated culture.

\section{CONCLUSIONS}

In two experimental models of the CNS pathology (multiple sclerosis, parkinsonism) the structural disturbances in neurons are accompanied by the changes in behavioural reactions. Increase in the number of T-lymphocytes, macrophages and MDA content in the brain as well as decrease of thymus hormone thymulin level in blood are inherent to animals of both experimental models. Melatonin injections showed protective effects on CNS neuronal structure (cerebral cortex, substantia nigra) and weakened negative shifts in behaviour in both animal models of experimental neurodegenerative pathology. Neuroprotective effects of melatonin is largely mediated by positive changes in immune system, neuroinflammation and oxidative stress. Positive melatonin action on immune system, CNS structure and functioning were more pronounced in the young mice with multiple sclerosis model. Melatonin can be considered a promising pathogenetic agent in the treatment of neurodegenerative pathology, in particular, multiple sclerosis and parkinsonism. However therapeutic schemes for aging organisms require correction.

\section{SUMMARY}

The study aimed: a) to investigate changes of the immune system, neuroinflammation and oxidative stress factors; structural and functional CNS disorders in animals with models of neurodegenerative pathology and (b) to estimate the efficiency of their improving after melatonin administration. Results. The obtained data convincingly indicate that: 1) number of T-lymphocytes, macrophages, neural stem cells (determined by $\mathrm{CD}^{+}, \mathrm{Mac}^{+}$, nestin ${ }^{+}$-markers) and malondialdehyde (MDA) content increase in the brain of neurotoxin cuprizone-treated young and aging $129 / \mathrm{Sv}$ mice. Percentages of unchanged neurons in cerebral cortex, motor and emotional activity are decreased. Melatonin injections decreased the number of $\mathrm{CD}^{+}, \mathrm{Mac1}^{+}$-cells, the MDA content and increased thymus hormone thymulin level in blood of mice of both age groups. The decrease in the number of nestin ${ }^{+}$-cells was accompanied by an increasing number of

${ }^{23}$ Rodnichenko A, Labunets I. The study of the remyelinating effect of leukemiainhibitor factor and melatonin on the toxic cuprizone model of demyelination of murine cerebellar cells culture in vitro. Cell and Organ Transplantology. 2018. 6(20. P. 182-187. DOI :10.22494/cot.v6i2.90. 
unchanged neurons and improving behavioral reactions. (2) MDA and active macrophages contents increase in the brain of adult Wistar rats with hemiparkinsonism (HP) induced by neurotoxin 6-hydroxydopamine. The blood thymulin level, number of unchanged neurons in substantia nigra of middle brain and motor activity decreased and anxiety increased. The activity of brain macrophages, MDA content decreased and thymulin level increased in melatonin- treated rats with HP. Melatonin increased the number of unchanged neurons in substantia nigra and improved behavioural indices. Conclusions. Positive effects of melatonin on CNS disturbances in animals with models of multiple sclerosis and HP were mainly mediated by changes in study pathogenic factors.

\section{REFERENCES}

1. Mishchenko T.S., Shulga O.D., Bobryk N.V., Shulga L.A. Multiple Sclerosis: Global Perspectives. Ukr Med Chasopis-Ukr Med J. 2014. 101(3). P. 84-87 [Ukrainian].

2. Karaban I.N., Karaban N.V., Karasevych N.V. The ways of neuroprotection in Parkinson's disease. INJ. 2011. № 6. P. 95-99 [Russian].

3. Abdurasulova I.N., Klimenko V.M. The role of immune and glial cells in neurodegeneration processes. Med. Akad. Zh. 2011. 11(1). P. 12-29 [Russian].

4. Guo J.-D., Zhao X., Li Y. et al. Damage to dopaminergic neurons by oxidative stress in Parkinson's disease (Review). Int J. of molecular medicine. 2018. 41. P. 1817-1825. doi:10.3892/ijmm.2018.3406.

5. Gonzalez H., Pacheco R. T-cell-mediated regulation of neuroinflammation involved in neurodegenerative diseases. $J$. Neuroinflammation. 2014. 11(201). 11 p. DOI: 10.1186/s12974-014-0201-8.

6. Csaba G. The immunoendocrine thymus as a pacemaker of lifespan. Acta Microbiol.Immunol. Hung. 2016. 63(2). P. 139-158. DOI: 10.1556/030.63.2016.2.1.

7. Labunets I.F., Rodnichenko A.E., Vasiliev R.G. Capacity of bone marrow granylocyte and macrophage precursors in mice of different strains for in vitro colony formation under changed thymuline level in the organism and cell cultures. Genes \& Cells. 2017. 12(2). P. 97-103. DOI: 10.23868/201707021.

8. Haddad J.J., Hanbali L.H. The anti-inflammatory and immunemodulatory activity of thymulin peptide is NF-kB dependent and involves the downregulation of I kB- $\alpha$. Am. J. Med. Biol. Res. 2013.1(2). P. 41-49.DOI: 10.12691/ajmbr-1-2-2.

9. Sarlak G., Jenwitheesuk A, Chetsawang B., Govitrapong P. Effects of melatonin on nervous system aging: neurogenesis and neurodegeneration. J. Pharmacol. Sci. 2013. 123. P. 9-24. PMID:23985544. 
10. Wurtman R. Multiple sclerosis, melatonin and neurobehavioral diseases. Front. Endocrinol. 2017. 8. Article 280 doi:10.3389/fendo.2017.00280.

11. Hardeland R. Melatonin in aging and diseases-multiple consequences of reduced secretion. Options and limits of treatment. Aging Dis., 3(2). P. 194-225. www.aginganddisease.org.

12. Labunets I.F. Age-related changes in the melatonin and thymulin biorhythms as risk factors for human neurodegenerative diseases. Gerontol\&Geriatric Stud. 1(2). GGS.000506.2017-5 p.

13. Praet J., Guglielmetti C., Berneman Z. et al. Cellular and molecular neuropathology of the cuprizone mouse model: Clinical relevance for multiple sclerosis.Neubiorev.2014.47. P. 485-505. doi.org/10.1016/j. neubiorev.2014.10.004.

14. Labunets I.F., Rodnichenko A.E. Melatonin effects in young and aged mice with toxic cuprizone-induced model of demyelination. Adv. Gerontol. 2019. 32(3). P.338-346. [Russian]. PMID:31512419.

15. Labunets I.F., Chaikovsky Yu.B., Savosko S.I. et al. Effects of melatonin on the behavioral indices and structural characteristics of cerebral and spinal neurons of rats with experimental hemiparkinsonism. Neurophysiology. 2018. 50(1). P. 11-22. DOI 10.1007/s11062-018-9712-8.

16. Labunets I.F., Melnyk N.O., Rodnichenko A.E. et al. Cuprizoneinduced disorders of central nervous system neurons, behavioral reactions, brain activity of macrophages and antioxidant enzymes in the mice of different ages: role of leukemia inhibitory factor in their improvement. J. Aging Geriatr. Med. 2017. 1(2). 8 p. Doi: 10.4172/AGM.1000104.

17. Uchiyama M., Mihara M. Determination of malonaldehyde precursor in tissues by thiobarbituric acid test. Anal. Biochem. 1978. 86(1). P. 271-278. DOI: 10.1016/0003-2697(78)90342-1.

18. Amikishieva AV. Behavioral phenothyping: up-to date methods and equipment. Vestnik VOGiS. 2009. 13(3). P. 529-542.

19. Kang Z., Liu L., Spangler R. et al. IL-17-induced Act1-mediated signaling is critical for cuprizone-induced demyelination. J. Neurosci. 2012. 32(4) P. 8284-8292. DOI: 10.1523/JNEUROSCI.0841-12.2012.

20. Labunets I.F., Butenko G.M., Khavinson V.Kh. Effects of bioactive factors of the pineal gland on thymus function and cell composition of the bone marrow and spleen in mice of different age. Bull Exp Biol Med. 2004. 137 (5). P. 510-512. PMID: 15455131.

21. Labunets I.F., Talanov S.A., Vasilyev R.G. et al. Thymic hormones, antioxidant enzymes and neurogenesis in bulbus olfactorius of rats with hemiparkinsonism: effect of melatonin. Int. J. Phys. Pathophys. 2016. 7(4). P. 285-298. DOI: 10.1615/IntJPhysPathophys.v7.i4.10. 
22. Kashani I.R., RaJabi Z., Akbari M. et al. Protective effects of melatonin against mitochondrial injury in a mouse model of multiple sclerosis. Exp. Brain Res. 2014. 232(9). P. 2835-2846. DOI: 10.1007/s00221-014-3946-5.

23. Rodnichenko A, Labunets I. The study of the remyelinating effect of leukemia-inhibitor factor and melatonin on the toxic cuprizone model of demyelination of murine cerebellar cells culture in vitro. Cell and Organ Transplantology. 2018. 6(20. P. 182-187. DOI: 10.22494/cot.v6i2.90.

\section{Information about author:} Labunets I. F., Doctor of Medical Sciences, PhD, DSc, Head of the Experimental Modeling Laboratory of the Cell and Tissue Technologies Department State Institute of Genetic and Regenerative Medicine of the National Academy of Medical Sciences of Ukraine 67, Vyshgorodskaya str., Kyiv, 04114, Ukraine 